\title{
PERFORMANCE OF DIFFERENT DIAMOND CUTTING TOOLS IN FACE MILLING OF CEMENTED CARBIDE
}

\author{
A. Nestler*, A. Schubert \\ Chemnitz University of Technology, Professorship Micromanufacturing Technology, Chemnitz, Germany \\ *Corresponding author; e-mail: andreas.nestler@mb.tu-chemnitz.de
}

\begin{abstract}
More and more forming and punching tools as well as wear parts are made from cemented carbide. The large variety and the geometry of these components are often reasons for finish machining by milling, but the tool wear is very high. For the investigations, end mills with different diamond material tips or coatings are used. The cemented carbide specimens exhibit an average tungsten carbide particle size of $2.5 \mu \mathrm{m}$ and the binder material is cobalt with a proportion of $20 \%$. The cutting parameters are kept constant. For all tools a surface roughness depth $R z$ smaller than $1 \mu \mathrm{m}$ is achieved. The detailed analysis of the tool wear behaviour and the surfaces allows for an appropriate selection of the cutting material and contributes to an increase of the performance of machining cemented carbides by milling.
\end{abstract}

\section{Keywords:}

Cemented carbide; Diamond; Milling; Surface properties; Tool Wear

\section{INTRODUCTION}

Cemented carbides are metal matrix composites consisting of a high proportion of hard carbide particles and a metallic binder. Most of cemented carbide grades are composed of tungsten carbide (WC) and cobalt (Co). However, further elements can be added to gain specific properties. In general, cemented carbides are characterised by a high hardness and strength resulting in a good mechanical wear resistance. This is also valid for elevated temperatures. Furthermore, the Young's modulus is increased in comparison to steel or other alloys, which enables a high stiffness.

Consequently, cemented carbides are typically used for highly stressed components, especially parts subjected to high friction loads and wear. Well-known is the utilisation for metal cutting tools, e.g. drills, milling tools, indexable inserts, saw blades, or reamers. Further applications, among others, are parts for general wear protection (e.g. guides, support blades, runners, bearing rings, bushings, nozzles), textile industry (e.g. blades, scissors), and food industry (e.g. mixing arms, grinder components). Because of an increasing use of high-strength materials combined with growing demands concerning tolerances and surface properties, cemented carbides gain more and more importance for forming and punching tools, e.g. matrices, dies, drawing tools, or cutting rings.

However, regarding the superior properties, cemented carbides are difficult-to-machine materials. Electrical discharge machining (EDM) leads to significant tensile residual stresses in the surface layer [Merklein 2011]. Without the application of any subsequent polishing process the residual stresses measured in the WC particles amounted to approximately $1000 \mathrm{~N} / \mathrm{mm}^{2}$. In contrast, mechanical processes result in strong compressive residual stresses. For ground or milled surfaces values of about $-1500 \mathrm{MPa}$ [Merklein 2011] and -1600 MPa [Okada 2021], respectively can be obtained. The strong difference in the residual stress state combined with further detrimental effects in EDM like a recast layer contributes to a much higher sliding wear compared to ground surfaces [Bonny 2009]. For simple form elements like planes or roughing operations, grinding is the first choice. However, many parts are characterised by complex geometries. Such cemented carbide components are typically manufactured by EDM. This is an elaborate process because of long machining times. Furthermore, for each geometry a specific electrode has to be produced. Beyond that, post-processing like grit blasting is often required to remove the heataffected surface layer. An opportunity to reduce the machining time and the number of processes required is micro milling. Typical applications are moulds, forming and punching tools. For machining of a cemented carbide indexable insert mould including roughing and finishing two ball end mills with a spherical radius of $0.5 \mathrm{~mm}$ were used. The total material removal volume was about $100 \mathrm{~mm}^{3}$ and the machining time amounted to $3 \mathrm{~h}$ [Union 2020]. Nonetheless, the demands considering machine tools and end mills are very high. Owing to the high hardness of cemented carbides and especially the WC particles, diamond tools are recommended. However, tool wear is a crucial point. 
Most of investigations have been realised with tools from Polycrystalline diamond (PCD), which is a composite of polycrystalline diamond particles and a cobalt binder. The electrical conductivity of the metallic component enables a final tool shaping by EDM [Wu 2019b]. However, for a removal of the heat-affected zone, a reduction of the tool surface roughness, and the generation of a more homogeneous cutting edge a subsequent finishing by grinding is typically carried out [Nakamoto 2012, Suzuki 2020, Wu 2019a, Zhan2015]. Nonetheless, especially for single-edged end mills the tool wear is high [Nakamoto 2012, Wu 2019a, Wu 2019b, Zhan 2015]. Regarding machining of grooves the tool wear can be reduced markedly by using a multi-edged milling tool. A side milling cutter with a diameter of $25 \mathrm{~mm}$ and 200 teeth enables a high-precision machining of V-grooves [Suzuki 2020]. Typical wear mechanisms are abrasion on both the flank face and the rake face. Among others, this leads to an increase of the corner radius for the case that the depth of cut is higher than the original corner radius [Zhan 2015] and a reduction of the corner radius for very low depths of cut, which are smaller than the corner radius [Wu 2019b]. In addition, cutting edge chipping is observed [Zhan 2015] except for machining of cemented carbide with a very small WC grain size $(0.3 \mu \mathrm{m}$ in [Nakamoto 2012]). Furthermore, material adhesion on the tool surface can be detected. Analyses revealed that the adhered material is cemented carbide (WC, Co) [Zhan 2015] or tungsten trioxide $\left(\mathrm{WO}_{3}\right)$ [Nakamoto 2012]. The properties of the surfaces machined strongly depend on the material cutting mode. For ductile mode, smooth surfaces with low roughness values can be gained. On the other hand, brittle fracture of the ceramic particles entails surface defects like pores or grooves and material smearing. The material removal mode can be influenced by the machining parameters. Especially the feed per tooth combined with the corner radius is relevant. Small feeds and increasing corner radii enhance the probability for ductile mode in the range of the machined surface because of decreasing undeformed chip thicknesses [Wu 2019a, Wu 2019b]. Furthermore, the surfaces are often characterised by feed marks with distances corresponding to the feed per tooth [Nakamoto 2012, Wu 2019b, Zhan 2015]. On the one hand, the feed marks result from the kinematical roughness (determined by feed per tooth and corner radius), on the other hand from material (especially cobalt binder) ploughing and squeezing because of the comparatively high cutting edge radii referring to the undeformed chip thickness near the residual surface [Wu 2019b, Zhan 2015]. Moreover, the ploughing and squeezing can lead to material accumulation and adhesion on the tool. For the case that this material falls off the tool, some peaks on the machined surface can arise [Wu 2019b]. An interesting aspect is that the direction of the feed marks is mirror-inverted to the cutting motion [Nakamoto 2012, Wu 2019b]. Based on this, it can be concluded that the remaining feed marks result from the recut of the tool. Nonetheless, appropriate cutting conditions allow for specular surfaces with values for $R a$ smaller than $0.1 \mu \mathrm{m}$ [Nakamoto 2012, Wu 2019a, Zhan 2015].

Because of the high time and effort for manufacturing of the PCD tools combined with reduced hardness owing to the Co binder of PCD, chemical vapour deposition (CVD) diamond coated end mills of cemented carbide have been tested. The high diamond layer thickness of about $20 \mu \mathrm{m}$ leads to a significant rounding of the cutting edges. This results already after a very short machining time to a flaking of the coating at the rake face. Consequently, the cutting edge becomes "sharper" and the tool can be used for a longer time without any significant flaking of the coating at the flank face for the case that the feed per tooth is smaller than the diamond layer thickness. However, flaking of the coating at the rake face involves a decrease of the axial force. Furthermore, the reduction of the cutting edge radius caused by flaking leads to surfaces with distinctive feed marks [Okada 2016]. The know-how gained from the research was used for the development of tools with a special cutting edge treatment. By diamond layer removal at the rake face close to the cutting edge "sharp" cutting edges could be obtained. This allows for the generation of specular surfaces with a roughness of about $0.05 \mu \mathrm{m}$ for $R a$ [Okada 2018]. However, surfaces are characterised by several pores resulting from a detachment of the WC particles. Furthermore, crushed particles in the surface layer can be detected.

The current state of research on machining of cemented carbide shows, that milling is appropriate for finishing considering surface microstructure and residual stresses. This requires super-hard, especially diamond cutting materials. However, surface properties are influenced by tool wear and cutting edge geometry. So far, research has been focussed on PCD tipped and CVD diamond coated tools. Furthermore, there are no comparative studies for suchlike end mills.

Our investigations consider different binderless diamond cutting materials. Tool wear and surface properties are analysed and compared. The results enable a reasonable choice of an appropriate end mill.

\section{EXPERIMENTAL SET-UP AND METHODS}

\subsection{Material and specimens}

For the experimental investigations, specimens from the grade GB32 (boehlerit) were used. This cemented carbide grade consists of about $80 \%$ WC grains with a size of $2.5 \mu \mathrm{m}$ and $20 \%$ Co binder. Both percent values refer to the mass. The grade GB32 is especially assigned for wear protection, forming and punching tools, also at elevated temperatures. The prismatic specimens used for the experiments had a size of about $20 \mathrm{~mm} \times 25 \mathrm{~mm} \times 5 \mathrm{~mm}$. Manufacturing of the specimens was realised by a powder metallurgy process route. It is finished by sinter hot isostatic pressing (HIP) to guarantee a homogeneous microstructure which is free of pores. The material properties are summarised in Table 1.

Tab. 1: Properties of cemented carbide grade GB32 [Boehlerit 2018].

\begin{tabular}{lcc}
\hline Property & Value & Unit \\
\hline Density & 13.55 & $\mathrm{~g} / \mathrm{cm}^{3}$ \\
Hardness HV30 & 1025 & $\mathrm{HV} 30$ \\
Compressive strength & 4200 & $\mathrm{~N} / \mathrm{mm}^{2}$ \\
Transverse rupture strength & 2800 & $\mathrm{~N} / \mathrm{mm}^{2}$ \\
Fracture toughness & $\geq 24.0$ & $\mathrm{MPa} \cdot \mathrm{m}^{1 / 2}$ \\
Young's modulus & 530 & $\mathrm{GPa}$ \\
Thermal expansion coefficient & $6.0 \cdot 10^{-6}$ & $\mathrm{~K}^{-1}$ \\
\hline
\end{tabular}

\subsection{Tools}

For the investigations, four different types of end mills were used. However, all diamond cutting materials considered are binderless. The CVD diamond and the UltraDiamond tipped end mills are single-edged standard catalogue tools (DTS - Diamond Tooling Systems). The customised end mill from Medidia with a solid MCD (monocrystalline diamond) cutting part is single-edged, too. The CVD 
diamond coated end mills from Union Tool are doubleedged. Independent of the cutting material, the cutting diameter of the end mills is $1 \mathrm{~mm}$ and the corner radius amounts to $0.1 \mathrm{~mm}$. Moreover, the nominal rake angles are $0^{\circ}$. Table 2 represents a summary of the clearance angle and the cutting edge angle of the minor cutting edge (front face). Fig. 1 shows SEM micrographs of the cutting part (overview) and the corner (detail).

Tab. 2: Angles of the minor cutting edges of the end mills.

\begin{tabular}{lcc}
\hline Tool & $\begin{array}{c}\text { Clearance } \\
\text { angle }\end{array}$ & $\begin{array}{c}\text { Cutting edge } \\
\text { angle }\end{array}$ \\
\hline CVD diamond & $12^{\circ}$ & $1.5^{\circ}$ \\
UltraDiamond & $14^{\circ}$ & $3^{\circ}$ \\
MCD & $7^{\circ}$ & $1^{\circ}$ \\
CVD diamond coating & $17^{\circ}$ & $4^{\circ}$ \\
\hline
\end{tabular}

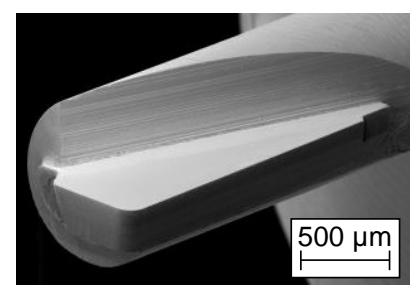

a) Cutting part CVD diamond

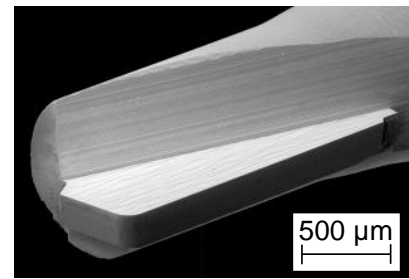

c) Cutting part UltraDiamond

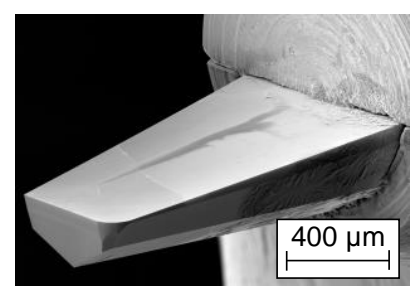

e) Cutting part MCD

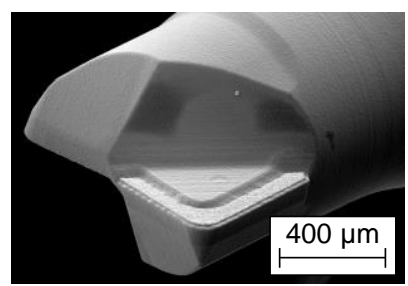

g) Cutting part CVD diamond coating

Fig. 1: SEM micrographs of diamond end mills.

The CVD diamond and the UltraDiamond tips are brazed on solid carbide shanks. The final geometry of the cutting edges is realised by laser ablation. This process results in a wavelike appearance of the flank faces and entails a cutting edge chipping and roughness $R z$ of about $1 \mu \mathrm{m}$. The cutting edge radius is in the range of circa 1 to 2 micrometres. For the UltraDiamond tipped tool, an increased roughness of the rake face and a small chamfer on the minor flank face with a width of about $7 \mu \mathrm{m}$ can be detected. The solid MCD cutting part is fixed in a multi-piece steel shank. The grinding and polishing of the rake face and the flank faces leads to a surface roughness $R z$ of only a few nanometers and sharp cutting edges without significant chippings. The cutting edge radius of the coated end mills is with about $5 \mu \mathrm{m}$ larger than for the other tools. Furthermore, adjacent to the cutting edge radius the rake angle is negative and constitutes circa $-60^{\circ}$. The thickness of the diamond coatings, which are removed at the rake faces close to the cutting edges, amounts to approximately $20 \mu \mathrm{m}$.

\subsection{Experimental procedure}

The experiments were carried out on a high precision machining centre of the type KERN Pyramid Nano. The cemented carbide specimens were clamped on a threecomponent dynamometer using a baseplate, three dowel pins as stops, and three eccentric fixture clamps consisting of a steel screw with an eccentric head and a hexagon brass washer (Fig. 2).

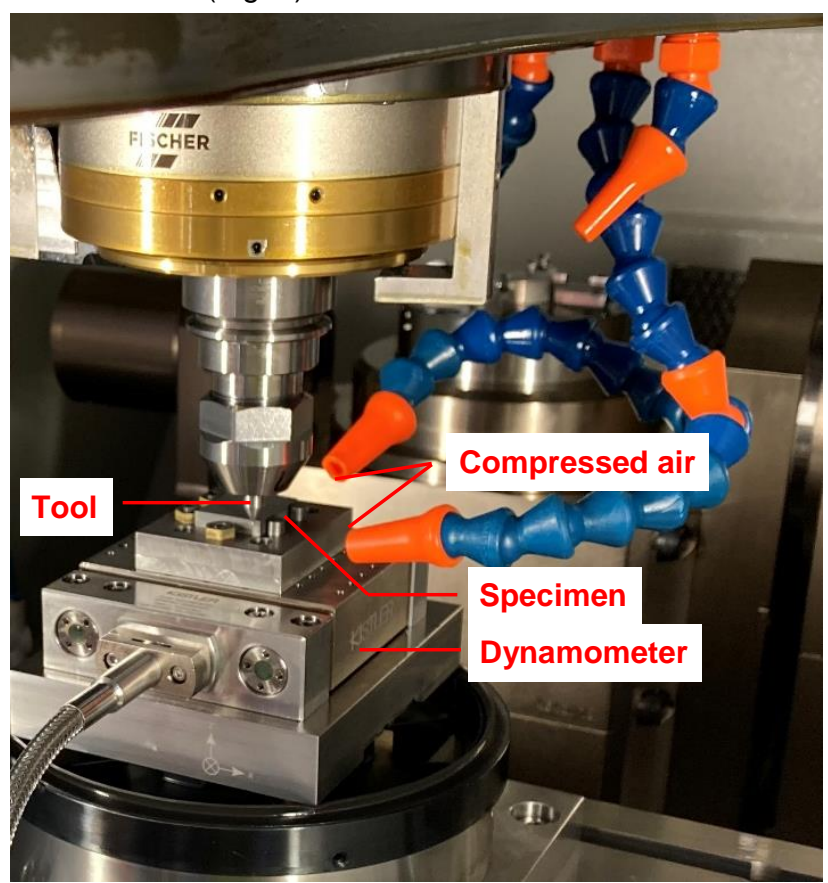

Fig. 2: Experimental set-up for cemented carbide milling.

A removal of the surface layer on a face with a size of approximately $20 \mathrm{~mm} \times 25 \mathrm{~mm}$ was realised by grinding. For roughing a tool with a diamond grain size D126 and a galvanic nickel bonding was used. Finishing was conducted with a resin and ceramic bonded D15 mounted point. For the face milling experiments each specimen was machined with a separate tool. The direction of feed motion was parallel to the edges with a length of about $25 \mathrm{~mm}$. All tests were realised with the same cutting parameters given in Tab. 3. The standard feed per tooth was $5 \mu \mathrm{m}$. However, for the double-edged CVD diamond coated tools the surface generation is more complex. There is a strong influence of the deviation of the axial position of the minor cutting edges to each other caused by production or wear. If both cutting edges do not have almost the same axial position, the surface is primarily or even completely generated by the cutting edge which is closer to the end face of the specimen. This means that for a double-edged end mill a feed per tooth of $5 \mu \mathrm{m}$ may act like a feed per tooth of $10 \mu \mathrm{m}$ referring to the surface structure. Because of this phenomenon a feed per tooth of $2.5 \mu \mathrm{m}$, which 
corresponds to a feed of $5 \mu \mathrm{m}$, was also applied for the CVD diamond coated tools. The investigations were realised with two tools. Each end mill was used for a separate specimen.

Tab. 3: Cutting parameters.

\begin{tabular}{lcc}
\hline Parameter & Value & Unit \\
\hline Cutting speed $v_{\mathrm{c}}$ & 50 & $\mathrm{~m} / \mathrm{min}$ \\
Depth of cut $a_{\mathrm{p}}$ & 0.05 & $\mathrm{~mm}$ \\
Width of cut $a_{\mathrm{e}}$ & 0.1 & $\mathrm{~mm}$ \\
Feed per tooth $f_{\mathrm{z}}$ & $5 / 2.5$ & $\mu \mathrm{m}$ \\
\hline
\end{tabular}

The experiments were performed dry, but with supply of compressed air by two nozzles for chip removal and tool cooling. During machining passive force, feed force, and feed perpendicular force were recorded using a charge amplifier and a LabVIEW programme. Because of the long machining time, sample rate was set to $500 \mathrm{~Hz}$. For the evaluation of cemented carbide machining the mean values of the passive force close to the beginning (path 20) and near the end (path 190) were used. The tool wear was estimated by SEM micrographs applying a secondary electron detector of the instrument Zeiss EVO 25.

\subsection{Surface evaluation}

For a qualitative characterisation of the surface microstructure SEM micrographs of the middle area of the surfaces generated were recorded using a secondary electron detector of the instrument mentioned above. The surface roughness in the direction of feed motion was measured with a stylus instrument of the type Mahr LD 120. For each specimen 11 parallel roughness profiles were recorded. The measuring length was $4 \mathrm{~mm}$ and filtering of the profiles was done in accordance to ISO 11562. The spherical radius of the stylus tip was $2 \mu \mathrm{m}$ and the included angle of the cone amounted to $90^{\circ}$. The roughness profiles were used to examine the arithmetic mean surface roughness $R a$. For an areal determination of the surfaces, areas with a size of slightly larger than $2 \mathrm{~mm} \times 2 \mathrm{~mm}$ were captured by laser scanning microscopy applying the instrument KEYENCE VK-9700 and stitching feature. For each specimen, three measuring fields (left, middle, right) were detected. Analysing of the data started with an extraction of the measuring fields to reduce their size to $2 \mathrm{~mm} \times 2 \mathrm{~mm}$. Afterwards the surface areas were aligned by subtraction applying method of least squares. Furthermore, form removal was done by a second degree polynomial. Subsequent filtering was subject to the kind of parameters. For height parameters like arithmetic mean height $S a$ robust Gaussian filters were applied. The lowpass filter $\lambda_{\mathrm{s}}$ was $2.5 \mu \mathrm{m}$ and the high-pass filter $\lambda_{\mathrm{c}} 0.8 \mathrm{~mm}$. For the functional volume parameters like the dale void volume a robust Gaussian filter with a value of $0.25 \mathrm{~mm}$ was used. For the parameters of the Abbott curve, especially the reduced dale height $S v k$ a $0.25 \mathrm{~mm}$ double Gaussian filter defined in ISO 13565-1 was applied.

\section{RESULTS AND DISCUSSION}

\subsection{Tool wear}

The high hardness of the WC particles involves strong loads on the cutting edge in machining. Consequently, the dominant wear mechanisms are abrasion and cutting edge chipping. Fig. 3 shows SEM micrographs of the tool wear.

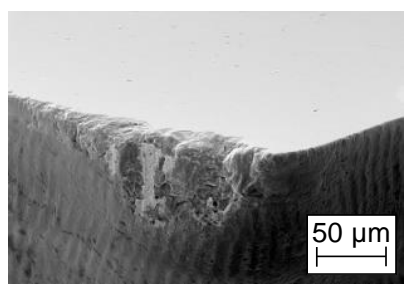

a) Overview CVD diamond

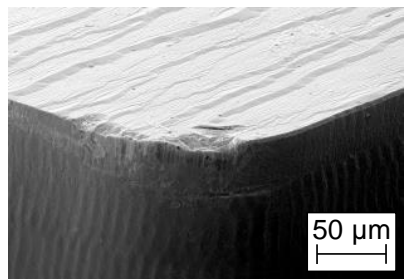

c) Overview UltraDiamond

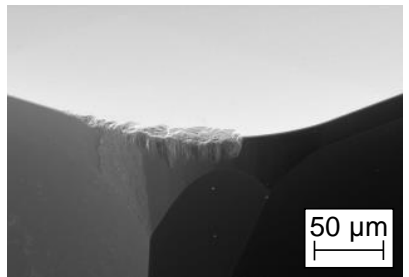

e) Overview MCD

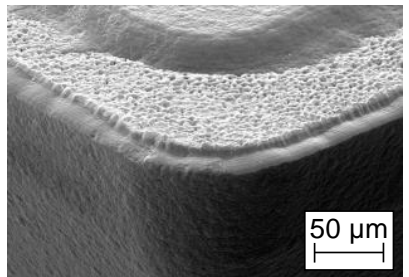

g) Overview cutting edge

1 CVD diamond coating after machining with $f_{\mathrm{z}}=5 \mu \mathrm{m}$

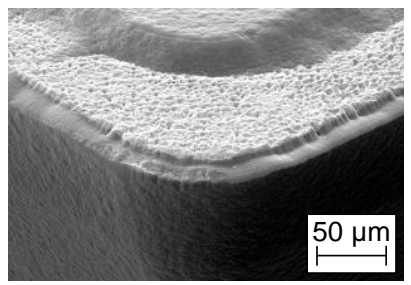

i) Overview cutting edge 2 CVD diamond coating after machining with $f_{\mathrm{z}}=5 \mu \mathrm{m}$

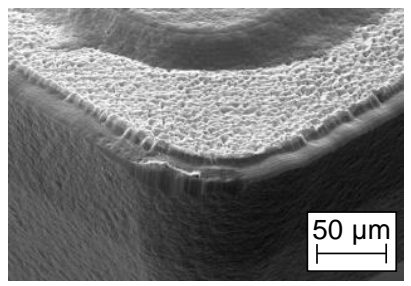

k) Overview cutting edge 1 CVD diamond coating after machining with $f_{z}=2.5 \mu \mathrm{m}$

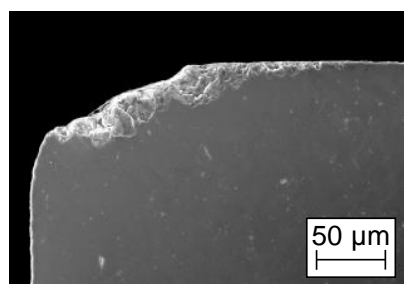

b) Rake face CVD diamond

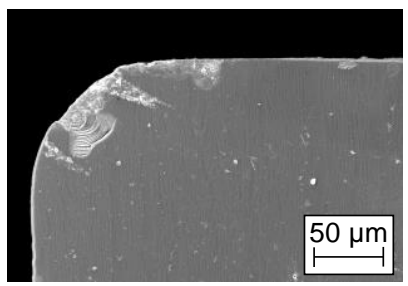

d) Rake face UltraDiamond

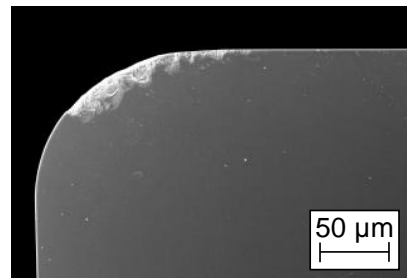

f) Rake face MCD

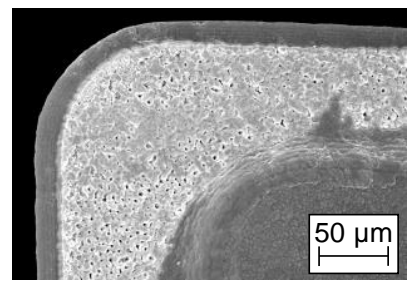

h) Rake face cutting edge 1 CVD diamond coating after machining with $f_{\mathrm{z}}=5 \mu \mathrm{m}$

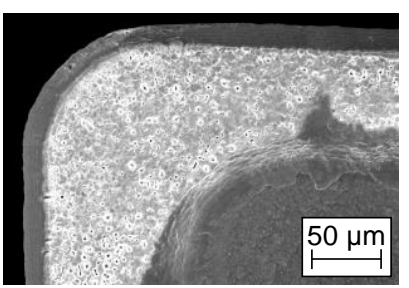

j) Rake face cutting edge 2 CVD diamond coating after machining with $f_{z}=5 \mu \mathrm{m}$

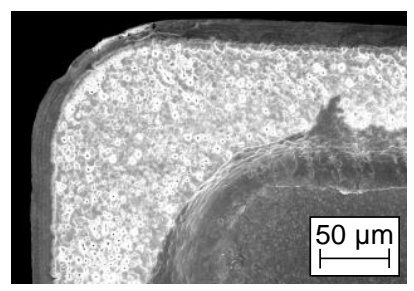

I) Rake face cutting edge 1 CVD diamond coating after machining with $f_{\mathrm{z}}=2.5 \mu \mathrm{m}$ 


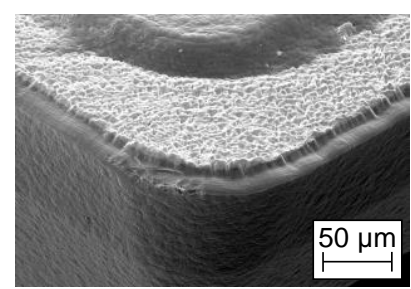

m) Overview cutting edge 2 CVD diamond coating after machining with $f_{z}=2.5 \mu \mathrm{m}$

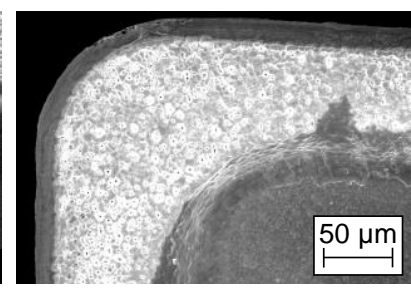

n) Rake face cutting edge 2 CVD diamond coating after machining with $f_{z}=2.5 \mu \mathrm{m}$
Fig. 3: SEM micrographs of tool wear.

Tool wear was most severe for machining with a CVD diamond tipped end mill. The minor flank face (Fig. 3a) shows a significant breakage of the cutting edge close to the corner. The flank wear land width amounts to approximately $70 \mu \mathrm{m}$. Furthermore, there are a significant displacement of the cutting edge in the direction of the rake face and severe cutting edge chippings (Fig. 3b). The wear could be reduced markedly by using an end mill with an UltraDiamond tip. The maximum flank wear land width is about $20 \mu \mathrm{m}$ (Fig. 3c) and there is only a small displacement of the cutting edge in the direction of the rake face. However, in the area of the corner, cutting edge chippings range up to a distance from the cutting edge of about $35 \mu \mathrm{m}$ (Fig. 3d). For the MCD tool, the flank wear land width (Fig. $3 e$ ) is in the same range like for the UltraDiamond tipped end mill, but the cutting edge chippings are smaller (Fig. 3f). In contrast to the different diamond tips, the diamond coatings do not exhibit significant cutting edge chippings (Fig. $3 g-$ Fig. $3 n$ ). This might be referred to the larger cutting edge radius and the negative rake angle close to the cutting edge. But, some built-up edges or material adhered and smeared on the flank face can be seen. This is especially the case for Fig. 3 and Fig. 3k involving a higher flank wear land width compared to the other cutting edges of these both tools. For both end mills, one of the two corners is more affected in this manner. The corners without any significant built-up edge or material smearing might be the ones, which are higher. Furthermore, it can be determined that a reduced feed per tooth leads to more severe built-up edges (Fig. 3k). This indicates, that the feed per tooth was lower than the minimum undeformed chip thickness resulting in more smearing and impeded material removal.

\subsection{Passive force}

The components of the resultant force depend on the cutting parameters, tool geometry and wear as well as further machining conditions. However, the surfaces are influenced by the forces, especially the passive force. Fig. 4 shows the influence of the cutting material and the feed per tooth on the passive force.

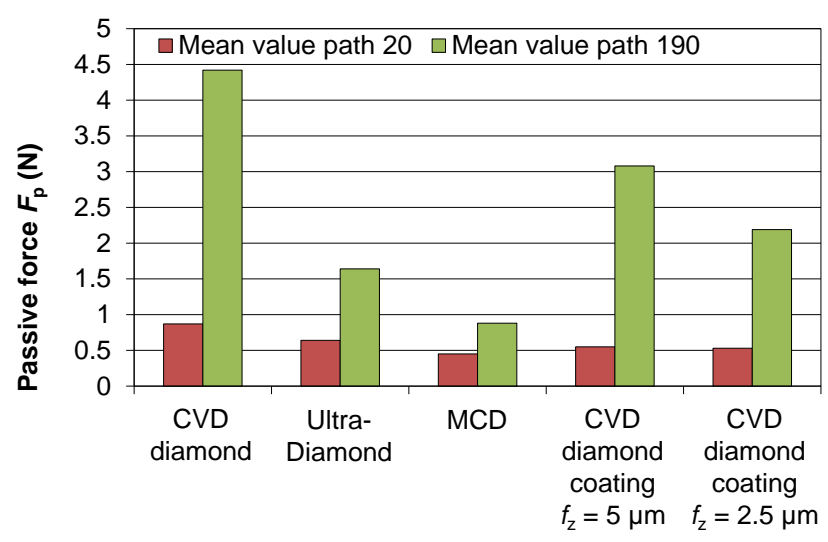

Fig. 4: Influence of the cutting material and the feed per tooth on the passive force considering different process phases.

The red bars (left) represent the forces close to the beginning of the process, that means after initial wear during running-in period. The passive forces just before reaching the right side of the specimen, which relates nearly to the end of the process, are illustrated by the green bars (right). It can be seen, that there is a significant increase of the passive force from the beginning to the end of the process being valid for all tests. This can be referred to a growth of the tool wear. For the CVD diamond tipped end mill the force values are the highest resulting from most severe tool wear. For the use of the MCD tool exhibiting sharp cutting edges the passive force and its increase are the lowest. The forces during milling with the CVD diamond coated tools are low at the beginning, but there is a strong increase because of cutting edge wear combined with the negative rake angle of the flank face coating. However, a reduced feed per tooth entails slightly lower passive forces.

\subsection{Surface microstructure}

The subsequent SEM micrographs show details of the specimen surfaces. The vertical direction of the micrographs corresponds to the direction of feed motion.

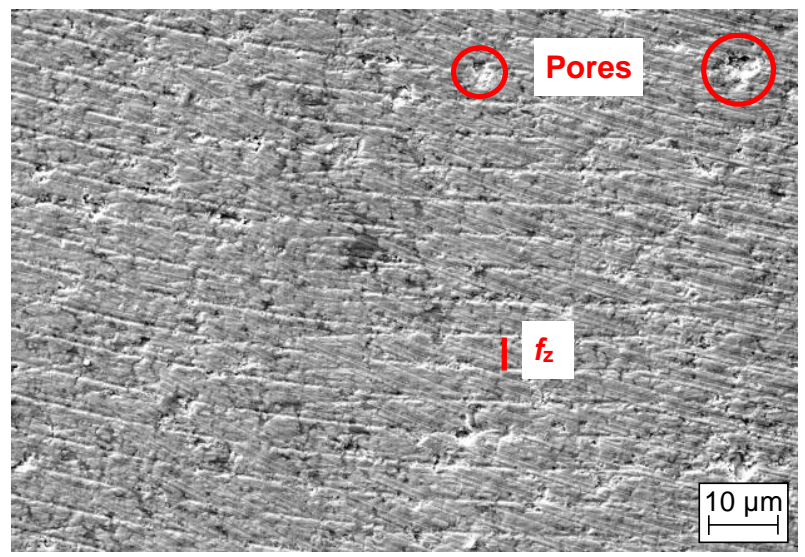

a) CVD diamond 


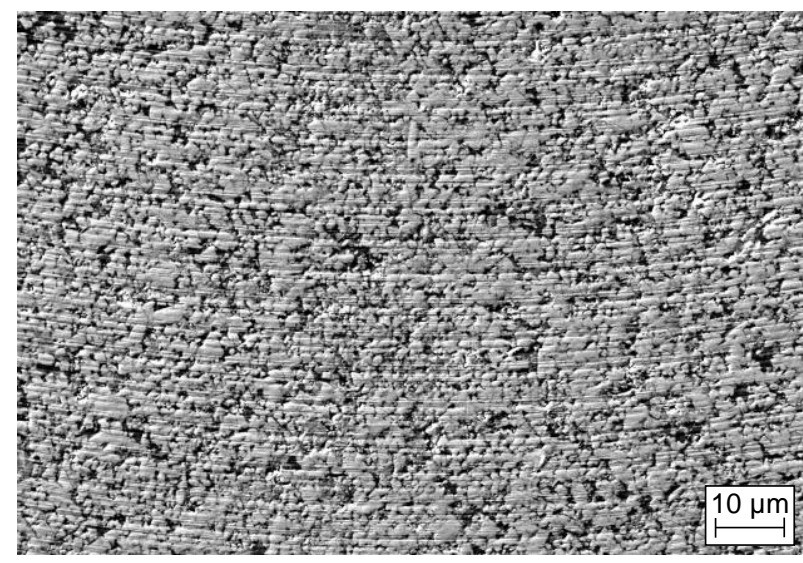

b) UltraDiamond

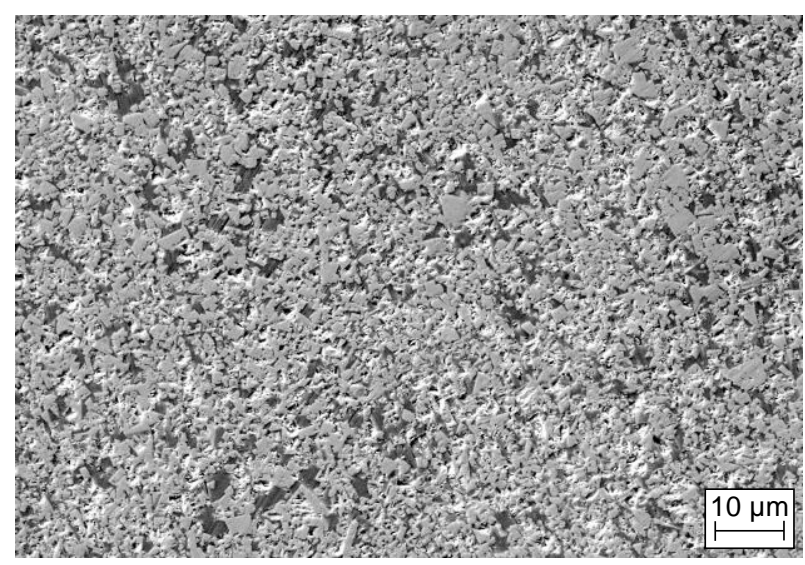

c) MCD

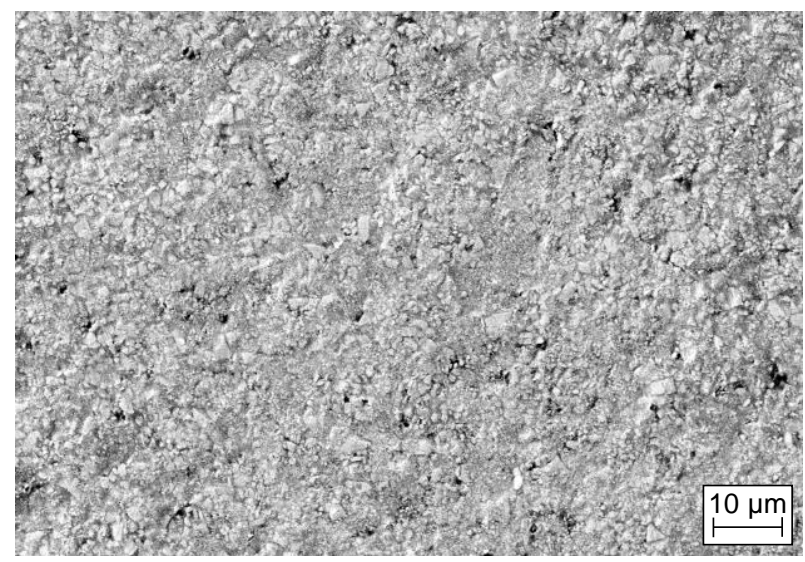

d) CVD diamond coating, $f_{z}=5 \mu \mathrm{m}$

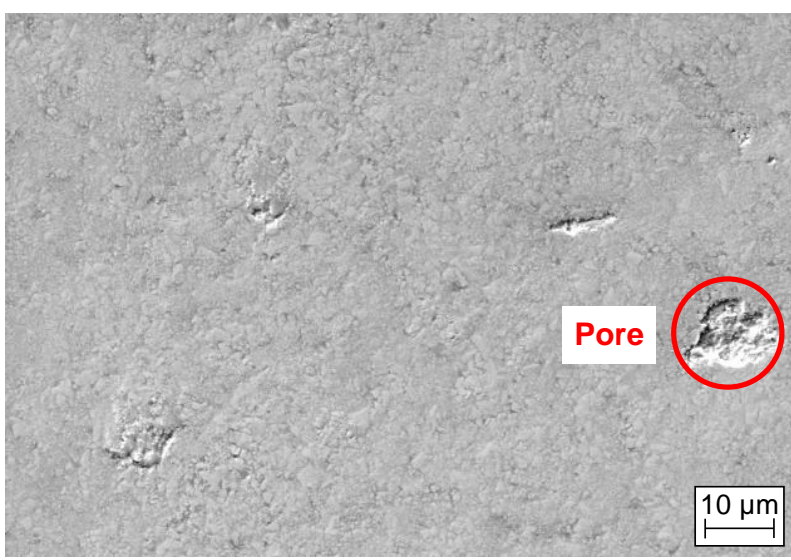

e) CVD diamond coating, $f_{z}=2.5 \mu \mathrm{m}$

Fig. 5: SEM micrographs of specimen surfaces.
For the surface generated with the CVD diamond tipped tool, distinct feed marks can be seen (Fig. 5a). The distance of the feed marks in the vertical direction corresponds to the feed $(5 \mu \mathrm{m})$. Concerning the curvature direction of the feed marks it can be concluded that the final surface arises by the recut of the cutting edge. This complies with the findings represented in [Nakamoto 2012, Wu 2019b]. In addition, the surface shows some pores, which may result from the removal of WC particles. Furthermore, material of the cobalt matrix is smeared on the WC particles. For the surface of the specimen machined with an UltraDiamond tipped end mill, the feed marks appear more shallowly (Fig. 5b). The comparatively low tool wear preserves the small cutting edge radius and the clearance angle, which impedes a significant smearing of the matrix material. Consequently, the surface is characterised by a higher porosity. It can be referred to WC particles, which are removed by the cutting edge. This behaviour is typical for particles with a high volume proportion above the cutting surface. After machining with a MCD tool the WC particles can be seen clearly (Fig. $5 \mathrm{c}$ ). The surface of the particles indicates ductile cutting. Because of the very sharp cutting edge, there is nearly no smearing of matrix material. Hence, there are no feed marks. Furthermore, the porosity is highest in comparison to the other surfaces because pores resulting from removed WC particles are not closed by the cobalt matrix. The larger cutting edge radius of the CVD diamond coating leads to severe smearing of the matrix material. This results in a decrease of the porosity (Fig. $5 \mathrm{~d}$ and Fig. 5e) compared to the other surfaces. Furthermore, some WC particles seem to be broken or crushed during machining. This complies with the results presented in [Okada 2021]. Most of WC particles are covered by matrix material. Especially for the specimen machined with the reduced feed per tooth of $2.5 \mu \mathrm{m}$ (Fig. 5e) the surface appears smooth, but exhibits some flaws like pores. This indicates that the minimum undeformed chip thickness is undercut.

For all surfaces, most of characteristic values are in the same range. Because of the small values and the inhomogeneous surfaces, their percentage spread is relatively high. The subsequent table gives an overview to the overall range of typical surface parameters. However, significant trends considering surface porosity are enlightened more in detail.

Tab. 4: Overall range of typical surface parameters.

\begin{tabular}{ccc}
\hline Parameter & Range & Unit \\
\hline$R a$ & $0.023-0.059$ & $\mu \mathrm{m}$ \\
$R z$ & $0.214-0.660$ & $\mu \mathrm{m}$ \\
$S a$ & $0.021-0.077$ & $\mu \mathrm{m}$ \\
\hline
\end{tabular}

The grade of surface porosity is reflected in the developed interfacial area ratio $S d r$, the reduced dale height $S v k$, and the dale void volume $V v v$. The following diagrams show the determined values. 


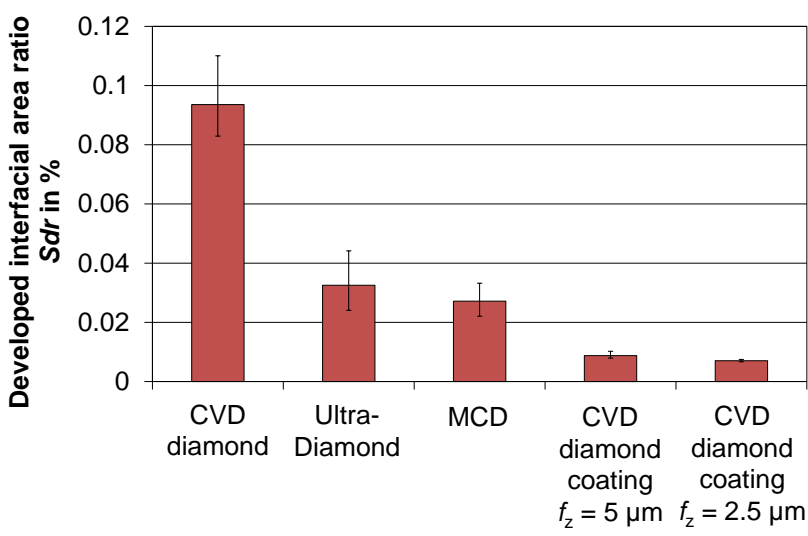

Fig. 6: Influence of the cutting material and the feed per tooth on the developed interfacial area ratio.

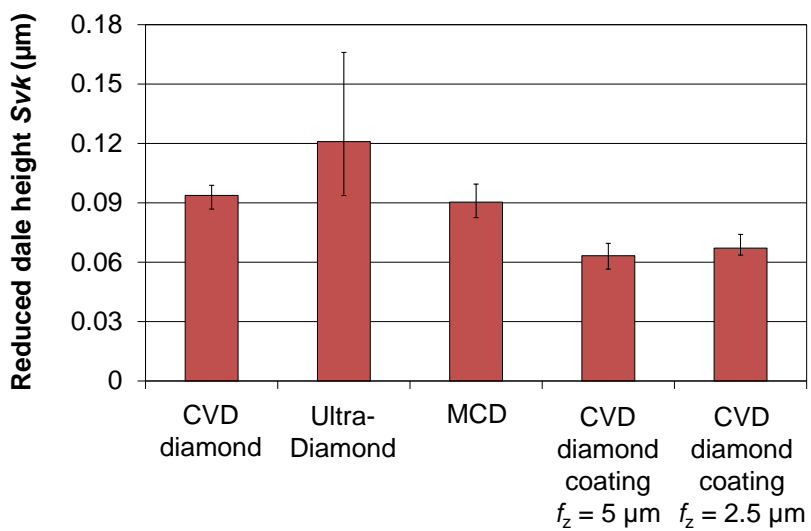

Fig. 7: Influence of the cutting material and the feed per tooth on the reduced dale height.

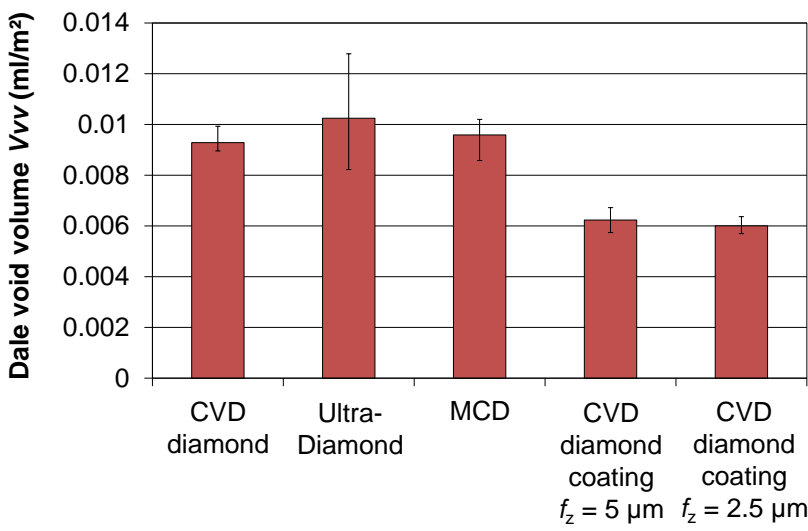

Fig. 8: Influence of the cutting material and the feed per tooth on the dale void volume.

The developed interfacial aria ratio is a measure for the microroughness. This means, a high number of hills and dales increases the Sdrvalue. As can be seen from Fig. $5 d$ and Fig. 5e, the surfaces generated by the CVD diamond coated tools are comparatively smooth. This resulted in the smallest Sdr values being similar for both feeds per tooth. However, the smaller feed led to the lowest growth of the surface. Furthermore, the spread is minor for both feeds per tooth. Machining with UltraDiamond or MCD cutting edges entails a high porosity of the surface (Fig. $5 b$ and Fig. 5c) determining higher Sdr values. Moreover, the tool wear progress causes a higher spread. Maximum developed interfacial area ratio is observed after milling with the CVD diamond tipped tool. This surface (Fig. 5a) is characterised by distinct feed marks as well as many pores and hills. Consequently, Sdr value is the highest. Beyond that, tool wear has a strong influence on the developed interfacial area ratio.

The number and size (volume) of the pores can be estimated by the reduced dale height and the dale void volume as integral parameters. Again, the values of the surfaces generated with the CVD diamond coated tools are the smallest. However, they are in the same range. The high porosity of the other surfaces involves increased values. The maximum values for the surfaces generated with the UltraDiamond tipped end mill may be referred to slight arc-shaped marks, which result from cutting edge chipping.

\section{SUMMARY}

The large variety and the geometry of cemented carbide components like forming and punching tools as well as wear parts are often reasons for finish machining by milling. However, the tool wear is very high.

For the investigations in tool wear and surface properties, single-edged end mills with CVD diamond, monocrystalline diamond (MCD), and UltraDiamond cutting tips are used. Furthermore, double-edged CVD diamond coated end mills with a partly removed coating layer on the rake face are applied. All end mills have a diameter of $1 \mathrm{~mm}$ and a corner radius of $0.1 \mathrm{~mm}$. The monolithic specimens with a size of the machined surface of about $20 \mathrm{~mm} \times 25 \mathrm{~mm}$ exhibit an average WC particle size of $2.5 \mu \mathrm{m}$. The binder material is cobalt with a proportion of $20 \%$. For the research the cutting speed $(50 \mathrm{~m} / \mathrm{min})$, the depth of cut $(0.05 \mathrm{~mm})$, and the width of cut $(0.1 \mathrm{~mm})$ are kept constant. The feed per tooth amounts to $5 \mu \mathrm{m}$. In addition, for a coated tool a feed per tooth of $2.5 \mu \mathrm{m}$ is applied. All experiments are carried out dry, but with support of compressed air for chip removal and tool cooling.

The CVD diamond tipped tool shows most severe tool wear. There is a strong change of the corner radius. In general, the sharp cutting edges of the diamond tips tend to chipping at the corner and the adjacent part of the minor cutting edge. The CVD diamond coatings prove to be more stable. There are only very small cutting edge chippings at the corner. However, material adhesion close to the cutting edge can be seen.

The passive force significantly increases with time for all tools. Because of the strong tool wear, highest values are obtained for the CVD diamond tipped tool. The application of the MCD tool results in the smallest values of the passive force and the least increase with cutting time. For the CVD diamond coated tools the decreased feed per tooth entails slightly lower passive forces.

In general, the surface roughness depth $R z$ achieved is smaller than $1 \mu \mathrm{m}$. However, surface microstructure differs from each other. For the application of the diamond coated tools, the surfaces are comparatively smooth. The use of the CVD diamond tipped tools results in distinct feed marks. Their direction indicates a generation during the recut. The very sharp cutting edges of the UltraDiamond and the MCD tool lead to surface pores. Consequently, the developed interfacial area ratio $S d r$, the reduced dale height $S v k$, and the dale void volume $V v v$ are increased. An appropriate selection of the cutting material allows for a predefined surface generation to increase the performance of tribological stressed components like forming tools. 


\section{ACKNOWLEDGEMENT}

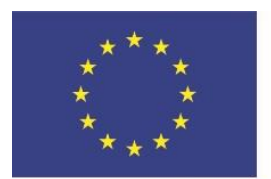

European Union

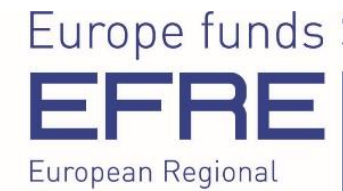

European Regional

Development Fund

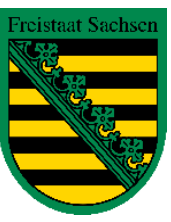

This project is co-financed by tax funds on the basis of the budget decided by the members of the Saxon State Parliament.

\section{REFERENCES}

[Boehlerit 2018] Tungsten carbide. Wear Protection \& Semi-Finished Products. BOEHLERIT GmbH \& Co. KG

[Bonny 2009] Bonny, K., et al. Influence of electrical discharge machining on the reciprocrating sliding wear response of WC-Co cemented carbides. Wear, March 2009, Vol.266, No.2, pp 8495. ISSN: 0263-4368

[Merklein 2011] Merklein, M., et al. Influence of machining process on residual stresses in the surface of cemented carbides. Procedia Engineering, 2011, Vol.11, pp 252257. ISSN: $1877-7058$

[Nakamoto 2012] Nakamoto, K., et al. A study on the quality of micro-machined surfaces on tungsten carbide generated by PCD micro end-milling. CIRP Annals - Manufacturing Technology, 2012, Vol.61, No.1, pp 567-570. ISSN: 00078506

[Okada 2016] Okada, M., et al. Mechanisms and characteristics of direct cutting of tungsten carbide using a diamond-coated carbide end mill. International Journal of Advanced Manufacturing Technology, September 2016, Vol.86, pp 18271839. ISSN: 0268-3768

[Okada 2018] Okada, M., et al. Evaluation of finished surface of cemented carbide by direct cutting using diamond-coated carbide end mill. Procedia CIRP, 2018, Vol.77, pp 114117. ISSN: 2212-8271

[Okada 2021] Okada, M., et al. Surface quality of cemented tungsten carbide finished by direct cutting using diamondcoated carbide end mill. Journal of Manufacturing Processes, January 2021, Vol.61, pp 8399. ISSN: 15266125

[Suzuki 2020] Suzuki, A., et al. Precision cutting of structured moulds of tungsten carbide with PCD milling tool. In: Proceedings of the $20^{\text {th }}$ International Conference of the European Society for Precision Engineering and Nanotechnology, EUSPEN 2020, Geneva, 812 June, 2020. pp 375376. ISBN: 978-0-9957751-7-6

[Union 2020] Tungsten Carbide End Mills. UDC Ball Series. UNION TOOL CO.

[Wu 2019a] Wu, X., et al. Investigation on the surface mechanism in micro milling of cemented carbide. International Journal of Refractory Metals \& Hard Materials, January 2019, Vol.78, pp 6167. ISSN: 0263-4368

[Wu 2019b] Wu, X., et al. Experimental Investigation on Direct Micro Milling of Cemented Carbide. Micromachines, February 2019, Vol.10, No.2, 147. ISSN: 2072-666X

[Zhan 2015] Zhan, Z., et al. Precision milling of tungsten carbide with micro PCD milling tool. International Journal of Advanced Manufacturing Technology, April 2015, Vol.77, pp 20952103. ISSN: 0268-3768 